\title{
A breath of fresh air
}

\author{
Staff Sheehan is a co-founder and the Chief Technology Officer at Air Company, a Brooklyn-based startup that uses \\ heterogeneous catalysis to transform $\mathrm{CO}_{2}$ into value-added products. Here, talking to Nature Catalysis, he takes us \\ on a journey from vodka and hand sanitizer into outer space.
}

Tell us a little about what Air Company is doing. What is the ultimate goal of the company?

The ultimate goal of Air Company is to contribute towards stopping climate change. More specifically, the goal of the company is to develop and deploy $\mathrm{CO}_{2}$ utilization technologies, and technological pathways, that enable capture and conversion of $\mathrm{CO}_{2}$ on the gigatonne scale prior to the year 2030. Some of the approaches we're working toward, such as $\mathrm{CO}_{2}$ to fuels, aim to displace fossil fuels using equivalent chemical compounds made from $\mathrm{CO}_{2}$ captured from the air. Other approaches that are part of our goals, such as when we convert $\mathrm{CO}_{2}$ to commodity chemicals or consumer goods, both displace fossil fuel inputs and sequester carbon in other forms.

Our technological approach focuses on $\mathrm{CO}_{2}$ hydrogenation using renewable $\mathrm{H}_{2}$. In short, Air Company utilizes $\mathrm{CO}_{2}, \mathrm{H}_{2} \mathrm{O}$, and renewable electricity to make chemicals, with oxygen as the only side product (like photosynthesis). As we scale our technology, the consumer goods you can see in-market today, such as our vodka and sanitizer can really be considered as the byproducts of our scale-up R\&D. However, our true product is the $\mathrm{CO}_{2}$ utilization technology that we are scaling to produce commodity chemicals and fuels such as alcohols, alkanes, and other compounds from gigatonnes of $\mathrm{CO}_{2}$.

How did you come up with the idea to produce vodka from $\mathrm{CO}_{2}$ ?

Air Vodka is a serendipitous product. It is the first product launched by Air Company that is currently in-market in New York City and a few other metropolitan areas in the US. It is the product of my co-founder, Gregory Constantine, and I meeting and starting Air Company. We met in 2017 in Israel, where we were both invited to participate in a series of events for Forbes under 30 - we had both been recently put on their 30 under 30 list. Greg came from a background in the spirits industry but had a drive to build an environmentally conscious organization that could have a truly global impact. Along with my chemistry background, I had spent some time doing traditional spirits distillation and had a basic understanding of what affected

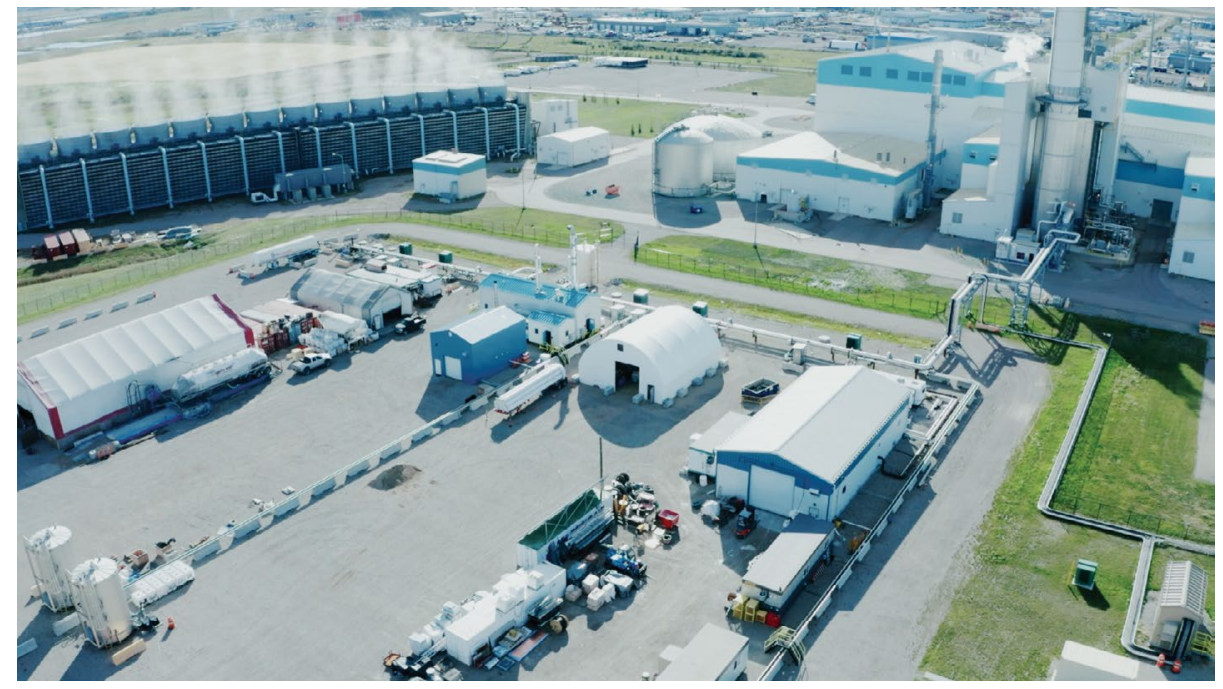

$\mathrm{CO}_{2}$-to-alcohol pilot plant (Air Company, Alberta, Canada). Credit: Air Company.

taste. Together, we were the right people, with the right technology, at the right time to launch this product as an example of how technology can transform $\mathrm{CO}_{2}$ into goods that help to fight climate change.

That being said, I wouldn't claim to be the first to have the idea to drink ethanol made from $\mathrm{CO}_{2}$. Throughout history, whenever chemists have been able to make ethanol, one of their first thoughts is whether it would be potable. Join that together with the rich history of ethanol synthesis from $\mathrm{CO}_{2}$ by hydrogenation and electrolysis on laboratory scales in the 1970s, 1980s, and 1990s, and I am sure that several chemists thought about drinking it back then. The contribution Air Company has brought to the table is the technology to ensure scale and high purity. One of Air Vodka's major accomplishments is that it has won gold medals in three of the most prestigious tasting competitions in the world: the San Francisco World Spirits Competition and the Luxury Masters in 2019, and the International Spirits Challenge in 2020. These were blind taste tests, so the liquid that we produce holds up on its own thanks to the selectivity of the catalysts that we developed, to avoid higher alcohols and other compounds that contribute to poor taste.
How did you end up also making hand sanitizer?

In March of 2020, the COVID-19 pandemic hit New York City. This was a scary and confusing time for many, but especially for people who lived in the five boroughs. Supply chain disruptions were headlining the news around the country, but one that was felt acutely in the city was the shortage of sanitizer. Several of the hospitals in Manhattan and Brooklyn did not have sufficient sanitization liquids to keep frontline workers safe amid all the uncertainty at the beginning of the pandemic.

At Air Company, since we had an alternative way of producing ethanol that was not affected by these supply chain disruptions, we decided to pivot all of our production fully to sanitizer for the duration of the pandemic to help our local community. Sanitizer requires United States Pharmacopeia (USP)-grade ethanol, and the ethanol we use for our vodka is much cleaner than USP grade, so we were able to use our feedstock to produce sanitizer. We manufactured and donated over 15,000 bottles of sanitizer to healthcare workers, frontline workers, and disadvantaged communities in NYC and beyond to try to help do our part when it seemed like the world was in disarray. 


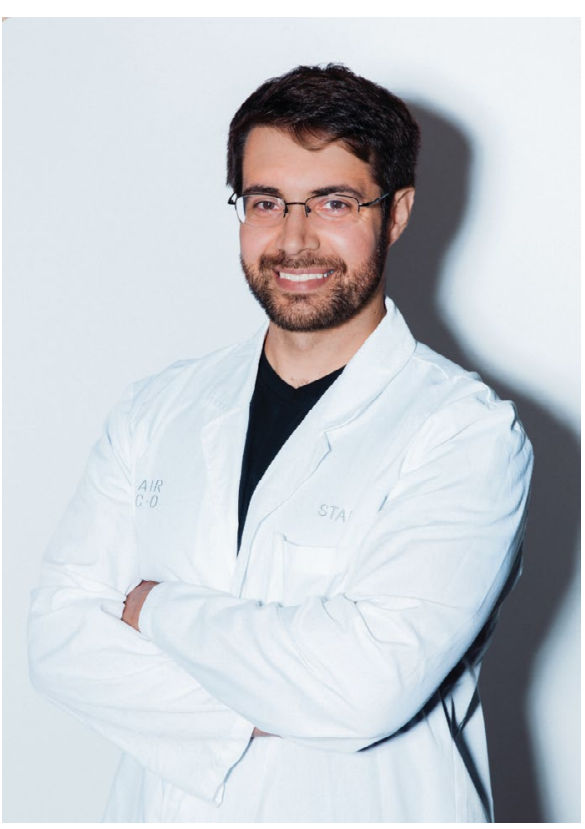

Staff Sheehan. Credit: Air Company

I have a distinct memory of driving up 6th Avenue in Manhattan in early April, 2020 with Air Company's director of sales. We had cases of sanitizer in the back of my truck to deliver to hospitals, and the city looked like a scene from a disaster movie with not a soul on the streets and none of the usual cars or traffic. Our hand sanitizer product (Air Spray) is what endured from that time, and we continue to offer it for sale and donation to underserved communities.

You were recently awarded a prize from NASA's $\mathrm{CO}_{2}$ Conversion Challenge. What was that for? Why is $\mathrm{CO}_{2}$ conversion of interest to NASA?

$\mathrm{CO}_{2}$ conversion is important to NASA because in space, and particularly on Mars, there is an abundance of it. The Martian atmosphere is over $95 \% \mathrm{CO}_{2}$, and on space stations, astronauts breathe out $\mathrm{CO}_{2}$ as a waste product. Finding ways to utilize that $\mathrm{CO}_{2}$ is important both for mass conservation during long-duration missions in space, and for in situ resource utilization on places like Mars.

In 2018, NASA announced their $\mathrm{CO}_{2}$ Conversion Challenge with the aim to produce glucose from $\mathrm{CO}_{2}$. The catch that made the competition interesting is that the pathway developed and proposed to NASA had to be entirely abiotic, that means no competitor was allowed to use biological organisms, enzymes, or materials derived from a biological organism. This made it very tricky to devise a pathway, and five teams (including Air Company) were awarded Phase 1 prizes for proposing feasible synthetic pathways.

The competition proceeded to Phase 2, where we had to demonstrate and build our abiotic pathway for $\mathrm{CO}_{2}$ conversion to glucose followed by a site visit and rigorous due diligence (such as sampling of all process streams) from NASA judges. Since we made alcohols from $\mathrm{CO}_{2}$, our pathway, naturally, used those alcohols as an intermediate. For NASA, we developed a downstream method to convert our alcohols into aldehydes, which was a straightforward step since aldehyde production from alcohols (for example, formaldehyde production) is done on large scales using thermocatalytic approaches. Then lastly, we had to develop a catalyst that would convert the aldehydes into 6-carbon sugars, which was the most challenging part. For this step, we screened several different combinations of metals and ligands that we believed would achieve the transformation efficiently. We ultimately settled on a successful one that we do hope to publish sometime in the future. After evaluation from NASA, our technology was awarded the first prize in Phase 2 of the $\mathrm{CO}_{2}$ Conversion Challenge, followed by two other finalist teams who also did excellent work using different pathways.

Alcohols and now sugars, is this part of a general plan to diversify the number of products you can produce?

The core of our technological approach has always been the conversion of $\mathrm{CO}_{2}$ to alcohols (primarily methanol and ethanol) as a building block to downstream products with greater market sizes and potential to sequester or mitigate $\mathrm{CO}_{2}$ emissions. As one of the largest potential markets, we've demonstrated production of kerosene from our alcohols, using an alcohol-to-jet conversion pathway for sustainable aviation fuel. Our goal is to become a supplier of both carbon-negative commodity alcohols, as well as downstream products where process integration can bring about technical advantages (such as higher conversion efficiency). Over the coming years, you'll see several consumer goods that are the byproduct of this technology development, but we have always been focused on the markets and commodities with the largest potential to sequester $\mathrm{CO}_{2}$ so that we can reach our gigatonne scale goals.

\section{What kind of business model do you operate under to achieve these scale goals?}

Air Company sells consumer goods in the near-term as a proof of concept for $\mathrm{CO}_{2}$-derived products, and because over the course of our scale-up R\&D, we produce liquids in quantities and purities suitable for these consumer goods. Our greatest asset, however, is the data we collect from these systems. For example, Air Company's current pilot scale system has a nameplate capacity of $960 \mathrm{~kg}$ of $\mathrm{CO}_{2}$ per day and operates $24 / 7$ - in essence, it is a $\mathrm{CO}_{2}$ utilization facility on the scale of one tonne per day. Using our catalysts and reactor design, we have demonstrated over 5,000 hours of continuous operation without any observable catalyst degradation or decrease in activity. This is a necessary part of scale-up R\&D regardless of whether or not the liquids produced from the plant are utilized. Our business model enables us to use the resulting alcohols from our $\mathrm{R} \& \mathrm{D}$ testing to make products today and bring consumers along on the journey of technology scale-up with us. In the long term, our business model is to build commodity-scale systems that can sequester hundreds of thousands of tonnes of $\mathrm{CO}_{2}$ per year using what we learned from our scale-up R\&D.

You described your pilot plant as a $\mathrm{CO}_{2}$ utilization facility. Does that mean that no $\mathrm{CO}_{2}$ emissions are generated by the operation of the plant? What about the $\mathrm{CO}_{2}$ capture process or production of the $\mathrm{H}_{2}$ used as co-reagent?

Yes, Air Company's tonne-per-day pilot plant is a $\mathrm{CO}_{2}$ utilization facility that uses flue gas captured post-combustion from an $860 \mathrm{MW}$ natural gas power plant, to produce alcohols. It's deployed at the Alberta Carbon Conversion Technology Centre in Canada, which is adjacent to the power plant and operates an amine scrubber to strip tonnes of $\mathrm{CO}_{2}$ from a flue gas slipstream for tenants piloting $\mathrm{CO}_{2}$ utilization technologies. In our system, we were able to develop a reactor and scale-up our catalyst to enable zero $\mathrm{CO}_{2}$ emissions from the plant itself, which was a technical milestone. In both $\mathrm{CO}_{2}$ hydrogenation and some syngas processes, achieving high carbon efficiency relies on operation of a recycle loop to reuse unreacted gases after an initial pass through the reactor. Coproduction of gaseous products, such as methane, can cause problems for such a gas recycle system, because light alkanes are challenging to convert to liquid under the same conditions that $\mathrm{CO}_{2}$ or $\mathrm{CO}$ and $\mathrm{H}_{2}$ react to form products. In our pilot system, we demonstrated conversion of $\mathrm{CO}_{2}$ to alcohols with no alkane coproduction at this industrial scale, which enables the plant to run with full gas recycle. This means that all the carbon that goes into the plant in $\mathrm{CO}_{2}$, comes out as carbon in liquid alcohols 
and enables us to convert essentially $100 \%$ of the $\mathrm{CO}_{2}$ to products without emissions at the plant. Upstream and downstream from the plant, processes that require electricity (such as $\mathrm{H}_{2} \mathrm{O}$ electrolysis for $\mathrm{H}_{2}$ production) do have a carbon impact, but our production facilities utilize renewable resources to keep the carbon intensity of that electricity below the amount of carbon sequestered in the alcohols. We published a paper in Frontiers in Climate earlier this year that describes our pilot system, how we source $\mathrm{CO}_{2}$ from the power plant that it's deployed next to, and lifecycle analysis for the carbon intensity of our alcohols in more technical detail (G. Pace and S. W. Sheehan, Front. Clim. https://doi. org/10.3389/fclim.2021.656108; 2021).

Is this scale-up required for your model to become profitable?

Sustainable $\mathrm{CO}_{2}$ sequestration or utilization is only truly functional when it is economic as well as environmentally sustainable. The small, consumer goods scales (such as vodka and sanitizer) could be profitable today if our goals were to remain on the small scale, with limited impact. However, since our company's goal is to have a significant impact toward fighting climate change, we are scaling and reinvesting aggressively. To be profitable or break-even on alcohol commodity scales, which are high volume and very low margin, large chemical production facilities must be constructed, on the order of 100 to 1,000 times the scales we're at today. That's our immediate goal in the coming two years, followed by achieving scale for sustainable fuel production, which is another 10 to 100 times larger than commodities. At these scales is when we truly begin to have an impact toward fighting climate change.

Interviewed by Benjamin Martindale

Published online: 18 November 2021 https://doi.org/10.1038/s41929-021-00706-X 